A product of the Ground-Water Resources Program

\title{
Documentation of a Conduit Flow Process (CFP) for MODFLOW-2005
}

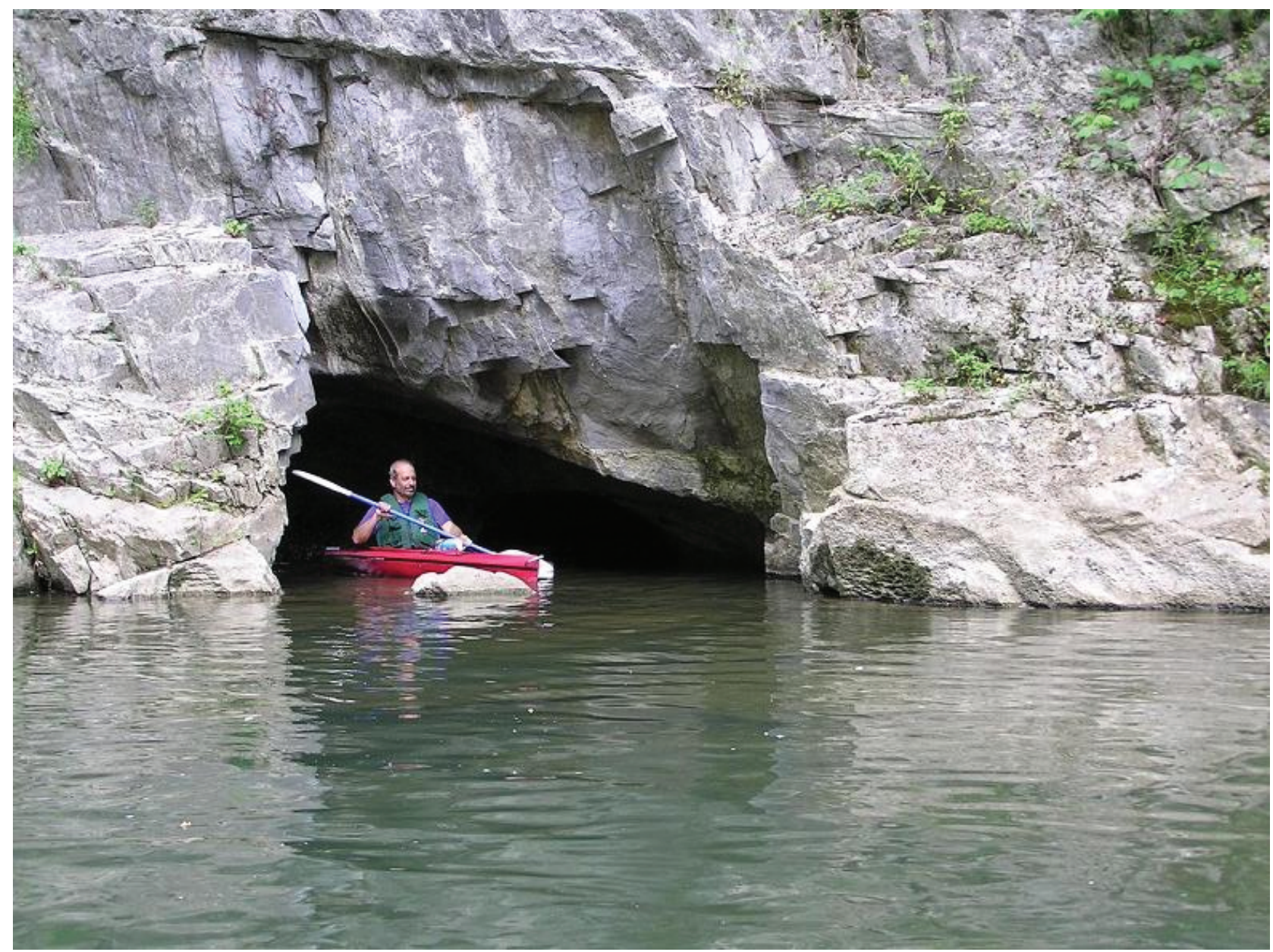

Techniques and Methods, Book 6, Chapter A24 